Article

\title{
Further Thermal Reduction of Reduced Graphene Oxide Aerogel with Excellent Rate Performance for Supercapacitors
}

\author{
Peihui Luo * and Ying Lin \\ Organic Optoelectronics Engineering Research Center of Fujian's Universities, College of Electronics and \\ Information Science, Fujian Jiangxia University, Fuzhou 350108, China; lylllj1996@163.com \\ * Correspondence: phluo@fjjxu.edu.cn; Tel.: +86-591-2353-7557
}

Received: 28 April 2019; Accepted: 23 May 2019; Published: 28 May 2019

Featured Application: The prepared three-dimensional graphene with porous structure and high electrical conductivity is an ideal electrode material for electrochemical energy storage devices, including supercapacitors and lithium ion batteries, etc.

\begin{abstract}
Preparation of pure three-dimensional graphene (3DG) with high rate performance for supercapacitors is critical for fast rate charge/discharge. Here, 3DG was prepared via thermal annealing of freeze-dried reduced graphene oxide (RGO) hydrogel under inert gas protection. The formed 3DG as an electrode material for supercapacitors revealed a specific capacitance of $115 \mathrm{~F} \cdot \mathrm{g}^{-1}$ at a current density of $1 \mathrm{~A} \cdot \mathrm{g}^{-1}$, and a high capacitance retention of $70 \%$ as current density increased to $40 \mathrm{~A} \cdot \mathrm{g}^{-1}$. The excellent rate capability was mainly attributed to the reserved porous structure and higher electrical conductivity for 3DG after thermal reduction than its RGO hydrogel precursor.
\end{abstract}

Keywords: three-dimensional graphene; thermal reduction; rate performance; supercapacitors

\section{Introduction}

Three-dimensional graphene (3DG) with a large surface area, high electrical conductivity, and a tailorable porous structure is an ideal electrode material and conductive scaffold for supercapacitors [1-3]. Various methods have been developed to prepare 3DG including self-assembly of graphene oxide (GO) in solution after hydrothermal [4-6] or chemical reduction [7], and template-assisted chemical vapor deposition [8,9], etc. [10,11]. Generally, the specific capacitance for supercapacitors based on directly prepared 3DG was in the range of 100 to $300 \mathrm{~F} \cdot \mathrm{g}^{-1}$ [12], much lower than the graphene theoretical capacitance of ca. $550 \mathrm{~F} \cdot \mathrm{g}^{-1}$ [13]. It was mainly due to aggregation and stacking of graphene sheets, largely reducing the specific surface area, which was difficult to avoid [14]. In consideration of this situation, one effective method was to prepare various composites based on 3DG via loading active electrode materials onto the 3DG framework, including transition metal compounds [15-19] and conducting polymers [20,21], etc. [22-25], for further improving the performance. The specific capacitance has been enhanced up to several thousand F.g ${ }^{-1}$ [26]. In addition to capacitive properties, rate performance is also important for supercapacitors, benefiting their fast charge/discharge. However, the specific capacitance for pure 3DG decreased greatly with increasing charge/discharge current density, especially for reduced graphene oxide (RGO) hydrogel [27]. The poor rate performance was mainly attributed to low electrical conductivity, hindering the rapid electron transport through electrode materials [28]. For improving electrical conductivity, RGO hydrogel has usually been further reduced via various chemical reducing agents [28] or thermal annealing with $\mathrm{H}_{2}$ at high temperature [29] after freeze-drying. Here, a simple heat treatment method was used to reduce 
freeze-dried RGO hydrogel, without using chemical agents and flammable $\mathrm{H}_{2}$. The obtained 3DG was applied as an electrode material for supercapacitors. It was found that the capacitance retention ratio was up to $70 \%$ when current density changed from 1 to $40 \mathrm{~A} \cdot \mathrm{g}^{-1}$. The excellent rate performance was mainly due to the intact porous structure and enhanced the electrical conductivityof3DG, compared with its RGO hydrogel precursor.

\section{Experimental}

\subsection{Preparation of $3 D G$}

Firstly, RGO hydrogel was prepared via hydrothermal reduction of GO according to our previous method [30]. The used GO aqueous solution of $2 \mathrm{mg} \cdot \mathrm{mL}^{-1}$ with a sheet size larger $500 \mathrm{~nm}$ was purchased from Nanjing XFNANO Materials Tech. Co., Ltd (Jiangsu, China). The formed hydrogel after freeze-drying was thermally treated under argon protection at $400{ }^{\circ} \mathrm{C}$ for $2 \mathrm{~h}$ with a heating rate of $10^{\circ} \mathrm{C} \cdot \mathrm{min}^{-1}$. The obtained 3DG solid was collected for further utilization.

\subsection{Characterization}

The morphology and structure of 3DG were observed using a MERLIN Compact field emission scanning electron microcopy (FESEM, ZEISS, Jena, Germany) and a Tecnai $\mathrm{G}^{2} \mathrm{~F} 30$ transmission electron microscope (TEM, FEI, Hillsboro, OR, USA). Raman and X-ray photoelectron spectroscopy (XPS) spectra were recorded on a LabRAM HR Evolution Raman spectrometer (HORIBA, Kyoto, Japan) with a $514 \mathrm{~nm}$ laser beam andan ESCALAB 250 Xi XPS spectrometer (Thermo Fisher Scientific, Waltham, MA, USA) with $\mathrm{Al} \mathrm{K \alpha}(1486.6 \mathrm{eV})$ as the $\mathrm{X}$-ray source and a pass energy of $30 \mathrm{eV}$, respectively.

\subsection{Electrochemical Measurement}

Electrochemical measurement for 3DG was performed on a 660D electrochemical workstation (CHI, Austin, TX, USA) in a three-electrode system with a saturated calomel (SCE) as the reference electrode. The electrolyte was $6 \mathrm{M} \mathrm{KOH}$ aqueous solution. The work electrode was prepared by pressing the paste on a platinum plate, formed via mixing 3DG, acetylene black and polytetrafluoroethylene (the mass ratio is 8:1:1) using ethanol as a dispersing agent. $\mathrm{KOH}$, acetylene black and polytetrafluoroethylene were purchased from Sinopharm Chemical Reagent Co., Ltd (Shanghai, China), and used as received without further purification. The mass loading for each electrode was ca. $1.77 \mathrm{mg} \cdot \mathrm{cm}^{-2}$. The counter electrode was an RGO coated platinum plate. And the specific capacitance was calculated by galvanostatic charge/discharge (GCD) curves similar to our previous method [30].

\section{Results and Discussion}

3DG was prepared by annealing of freeze-dried RGO hydrogel, formed firstly, via hydrothermal reduction of GO. As observed by SEM, 3DG after thermal treatment still exhibited porous structure with pore sizes distributed from several hundred nanometers to several micrometers (Figure 1a), demonstrating that further annealing of freeze-dried RGO hydrogel has less impact on its pore structure [31]. High magnification of SEM image (Figure 1b) clearly shows the wrinkle structure of graphene sheets stacking of 3DG, which is also confirmed via low magnification TEM (Figure 1c). Obvious graphene crystalline strips are also presented for 3DG, as imaged from high-resolution TEM (Figure 1d). 

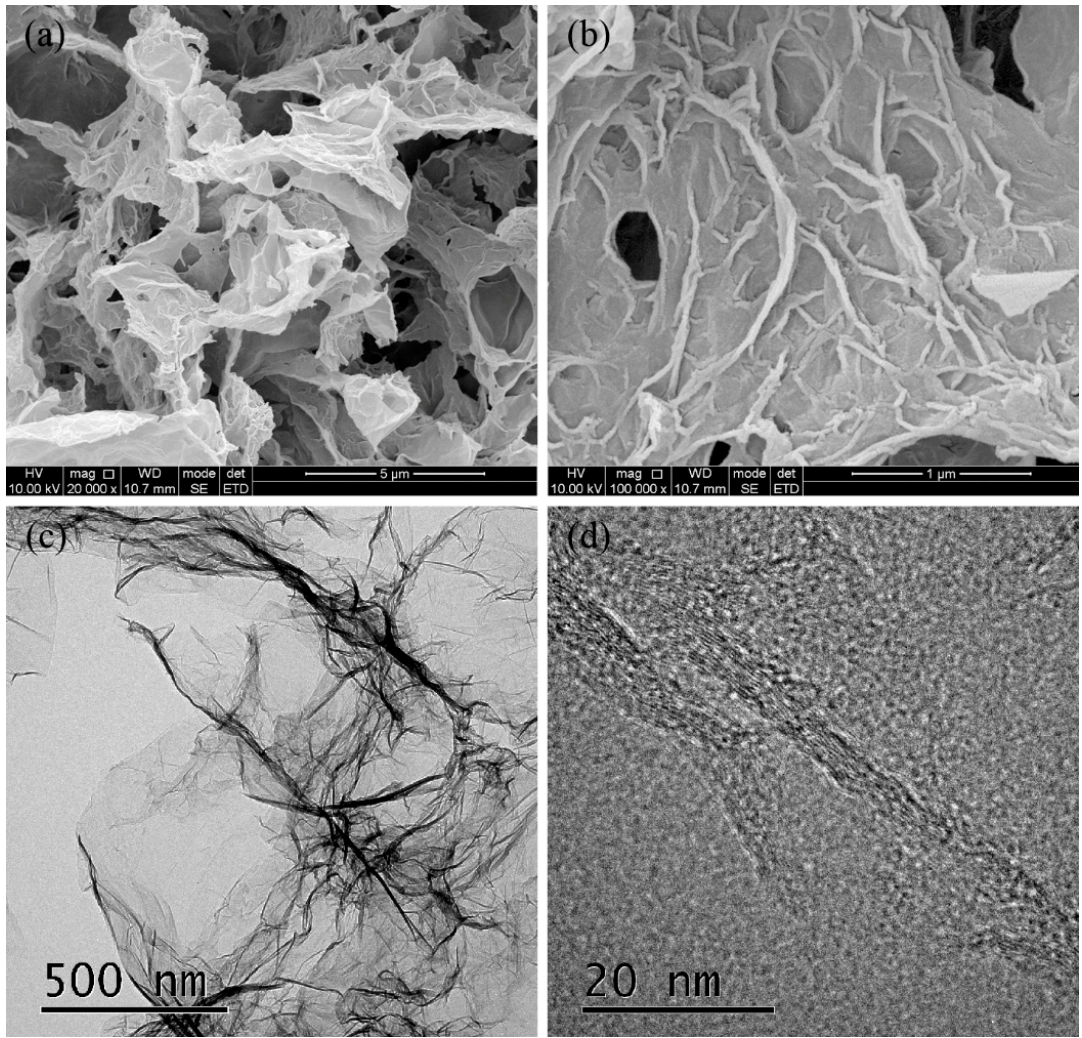

Figure 1. SEM (a,b) and TEM (c,d) images with different magnifications for 3DG. Low magnification $(\mathbf{a}, \mathbf{c})$, and high magnification $(\mathbf{b}, \mathbf{d})$.

Raman spectrum of 3DG (Figure 2a) shows the two characteristic peaks at 1335 and $1591 \mathrm{~cm}^{-1}$, attributed to $D$ and $G$ bands of graphene materials, respectively. The intensity ratio of $D$ and $G$ bands $\left(\mathrm{I}_{\mathrm{D}} / \mathrm{I}_{\mathrm{G}}\right)$ reflects the defect extent of materials. The $\mathrm{I}_{\mathrm{D}} / \mathrm{I}_{\mathrm{G}}$ value of prepared $3 \mathrm{DG}$ was measured to be 1.28 , obviously higher than that of its RGO hydrogel precursor with a value of 1.04 [30], indicating $\mathrm{sp}^{2}$ domains and edge defects were increased after thermal reduction [32]. C 1s XPS spectra of 3DG (Figure 2b) reveal typical peaks at ca. 286 and $289 \mathrm{eV}$ ascribed to $\mathrm{C}-\mathrm{O}$ and $\mathrm{COOH}$ groups, respectively. But the intensity for these peaks related to oxygenated groups is obviously weaker than the corresponding peaks from RGO hydrogel. Lower oxygen content for 3DG was also demonstrated by the ratio of C/O measured by XPS. 3DG had a C/O ratio of 7.1:1, higher than that of RGO hydrogel of 6.2:1 [30]. The oxygenated groups were further removed from the 3DG via thermal reduction, improving its electrical conductivity. Residual oxygenated groups of a small amount at 3DG surface benefit its contact with the electrolyte solution.
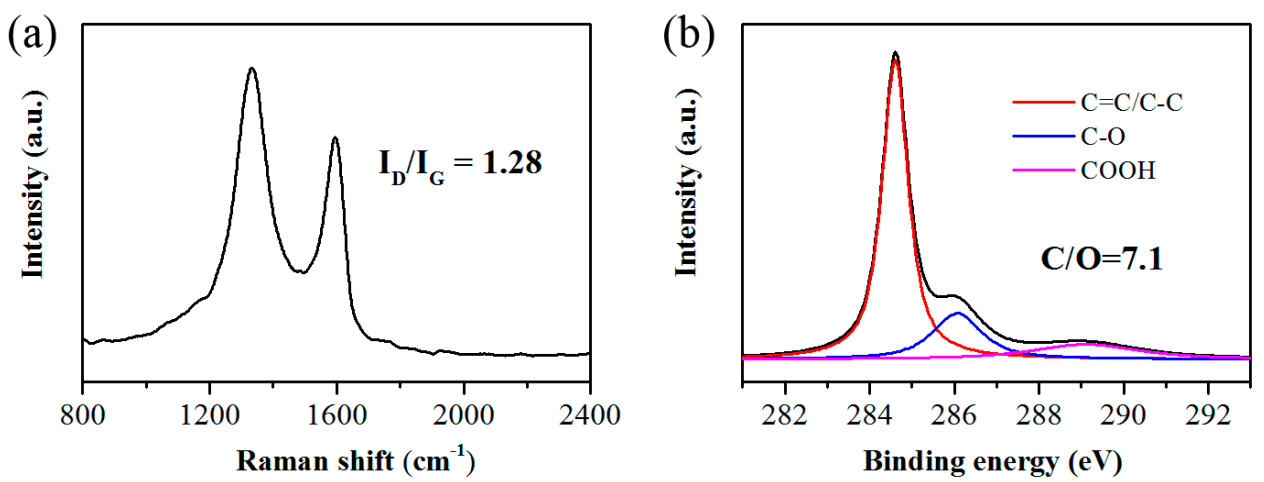

Figure 2. Raman spectrum (a) and C 1s XPS spectra (b) of 3DG. 
Cyclic voltammetry (CV) curves of the 3DG at various potential scanning rates are shown in Figure 3a. They always remain in a typical rectangular shape when the scanning rate changes from 10 to $100 \mathrm{mV} \cdot \mathrm{s}^{-1}$. While the $\mathrm{CV}$ curves for the RGO hydrogel distorted rapidly when increasing the scanning rate [30]. Therefore, the obtained 3DG via thermal treatment possesses better rate performance for supercapacitors, and no obvious redox peaks relevant to oxygenated groups are seen, supporting the electrical double-layer capacitance for 3DG. Figure 3b displays the GCD curve of 3DG at a current density of $1 \mathrm{~A} \cdot \mathrm{g}^{-1}$. According to this figure, the specific capacitance of 3DG at $1 \mathrm{~A} \cdot \mathrm{g}^{-1}$ was calculated to be $115 \mathrm{~F} \cdot \mathrm{g}^{-1}$, lower than RGO hydrogel $\left(198 \mathrm{~F} \cdot \mathrm{g}^{-1}\right.$ at ca. $\left.1 \mathrm{~A} \cdot \mathrm{g}^{-1}\right)$ [30]. Lower capacitance for 3DG was induced by the disappearance of pseudo-capacitance due to the removal of oxygenated groups via thermal reduction [33]. Furthermore, the elimination of oxygenated groups increased the hydrophobicity of 3DG, not benefiting its contact with electrolyte solution [29]. This value is comparable to commercial activated carbon with a typical specific capacitance of 80 to $120 \mathrm{~F}^{-\mathrm{g}^{-1}}$ [34,35]. The discharge curves at different current densities are shown in Figure 3c. According to these curves, specific capacitances were calculated and plotted versus current densities, as shown in Figure $3 \mathrm{~d}$. When current density increases up to $40 \mathrm{~A} \cdot \mathrm{g}^{-1}$, the specific capacitance for 3DG still remains $81 \mathrm{~F} \cdot \mathrm{g}^{-1}$. A $70 \%$ capacitance retention ratio for 3DG is presented when current density increasing 40 fold, obviously better than most reported results for 3DG, while the corresponding RGO hydrogel only showed a $16 \%$ capacitance retention when current density increased to ca. $20 \mathrm{~A} \cdot \mathrm{g}^{-1}$. Excellent rate performance was mainly resulted by the intact porous structure and better electrical conductivity for 3DG, which facilitated ion and electron transport, compared with RGO hydrogel.
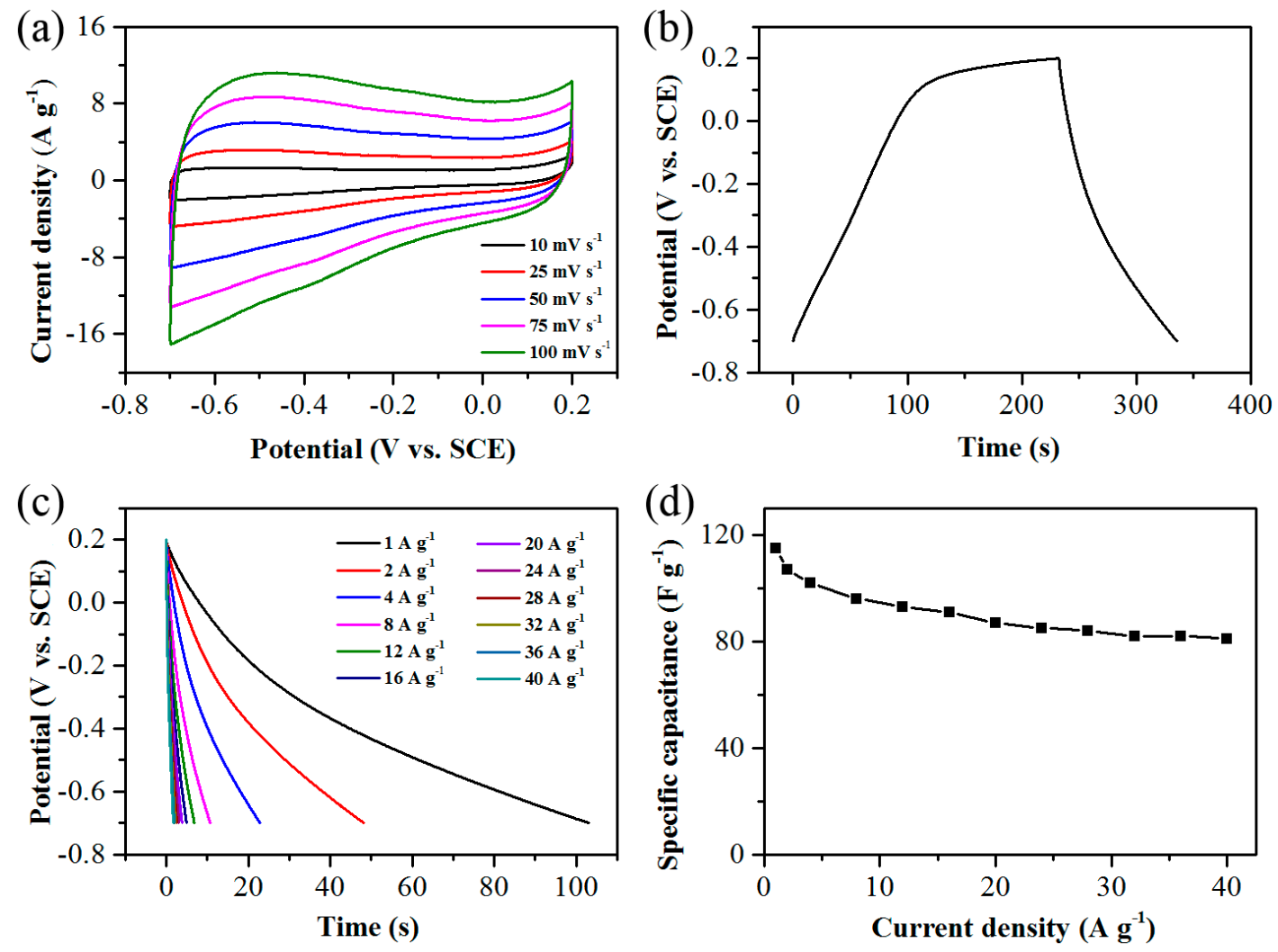

Figure 3. Electrochemical characterization of 3DG. CV curves at various scanning rates (a). Galvanostatic charge/discharge (GCD) curve at a current density of $1.0 \mathrm{~A} \cdot \mathrm{g}^{-1}(\mathbf{b})$. Galvanostatic discharge curves at different current densities (c). Specific capacitances versus current densities (d). 


\section{Conclusions}

3DG was prepared via thermal treatment of freeze-dried hydrothermally synthesized RGO hydrogel at a relatively low temperature. This method was simple and environment-friendly, avoiding common use of chemical agents and $\mathrm{H}_{2}$ at high temperature. Electrochemical measurement was carried out in $6 \mathrm{M} \mathrm{KOH}$ aqueous solution using a three electrode system. Supercapacitors based on 3DG as the work electrode revealed a specific capacitance of $115 \mathrm{~F}^{-\mathrm{g}^{-1}}$ at a current density of $1 \mathrm{~A} \cdot \mathrm{g}^{-1}$, and a high capacitance retention of $70 \%$ when the current density increased to $40 \mathrm{~A} \cdot \mathrm{g}^{-1}$. It was mainly attributed to the reserved porous structure and better electrical conductivity of3DG after simple thermal treatment. The excellent rate capability will facilitate 3DG based supercapacitors in fast rate charge/discharge applications.

Author Contributions: P.L. designed the experiments; P.L. and Y.L. performed the experiments; P.L. analyzed the data; P.L. wrote the paper.

Funding: This research was funded by the Natural Science Foundation of Fujian Province (2019J01878) and the Program for New Century Excellent Talents in Fujian Province University (Minjiaoke [2017] No. 52).

Conflicts of Interest: The authors declare no conflict of interest.

\section{References}

1. Wu, Y.; Zhu, J.; Huang, L. A review of three-dimensional graphene-based materials: Synthesis and applications to energy conversion/storage and environment. Carbon 2019, 143, 610-640. [CrossRef]

2. Xu, Y.; Shi, G.; Duan, X. Self-assembled three-dimensional graphene macrostructures: Synthesis and applications in supercapacitors. Acc. Chem. Res. 2015, 48, 1666-1675. [CrossRef] [PubMed]

3. Cao, X.; Yin, Z.; Zhang, H. Three-dimensional graphene materials: Preparation, structures and application in supercapacitors. Energy Environ. Sci. 2014, 7, 1850-1865. [CrossRef]

4. Song, Y.; Wang, H.; Liu, W.; Wang, $\mathrm{H}$.; Yan, $\mathrm{L}$. $\mathrm{Na}_{2} \mathrm{MoO}_{4}$ as both etcher for three-dimensional holey graphene hydrogel and pseudo-capacitive feedstock for asymmetric supercapacitors. J. Alloys Compd. 2019, 780, 55-64. [CrossRef]

5. Liu, X.; Zou, S.; Liu, K.; Lv, C.; Wu, Z.; Yin, Y.; Liang, T.; Xie, Z. Highly compressible three-dimensional graphene hydrogel for foldable all-solid-state supercapacitor. J. Power Sour. 2018, 384, 214-222. [CrossRef]

6. Xu, Y.; Sheng, K.; Li, C.; Shi, G. Self-assembled graphene hydrogel via a one-step hydrothermal process. ACS Nano 2010, 4, 4324-4330. [CrossRef]

7. Sheng, K.; Xu, Y.; Li, C.; Shi, G. High-performance self-assembled graphene hydrogels prepared by chemical reduction of graphene oxide. New Carbon Mater. 2011, 26, 9-15. [CrossRef]

8. Zheng, L.; Cheng, X.; Ye, P.; Shen, L.; Wang, Q.; Zhang, D.; Gu, Z.; Zhou, W.; Wu, D.; Yu, Y. Low temperature growth of three-dimensional network of graphene for high-performance supercapacitor electrodes. Mater. Lett. 2018, 218, 90-94. [CrossRef]

9. Chen, Z.; Ren, W.; Gao, L.; Liu, B.; Pei, S.; Cheng, H.M. Three-dimensional flexible and conductive interconnected graphene networks grown by chemical vapour deposition. Nat. Mater. 2011, 10, 424-428. [CrossRef] [PubMed]

10. Chabot, V.; Higgins, D.; Yu, A.; Xiao, X.; Chen, Z.; Zhang, J. A review of graphene and graphene oxide sponge: Material synthesis and applications to energy and the environment. Energy Environ. Sci. 2014, 7, 1564-1596. [CrossRef]

11. Yang, Z.; Chabi, S.; Xia, Y.; Zhu, Y. Preparation of 3D graphene-based architectures and their applications in supercapacitors. Prog. Nat. Sci. 2015, 25, 554-562. [CrossRef]

12. Chen, Z.; Jin, L.; Hao, W.; Ren, W.; Cheng, H.M. Synthesis and applications of three-dimensional graphene network structures. Mater. Today Nano 2019, 5, 100027. [CrossRef]

13. Sun, H.; Zhu, J.; Baumann, D.; Peng, L.; Xu, Y.; Shakir, I.; Huang, Y.; Duan, X. Hierarchical 3D electrodes for electrochemical energy storage. Nat. Rev. Mater. 2019, 4, 45-60. [CrossRef] 
14. Chen, K.; Song, S.; Liu, F.; Xue, D. Structural design of graphene for use in electrochemical energy storage devices. Chem. Soc. Rev. 2015, 44, 6230-6257. [CrossRef]

15. Liu, R.; Wen, D.; Zhang, X.; Wang, D.; Yang, Q.; Yuan, B.; Lü, W. Three-dimensional reduced-graphene $/ \mathrm{MnO}_{2}$ prepared by plasma treatment as high-performance supercapacitor electrodes. Mater. Res. Express 2018, 5, 065504. [CrossRef]

16. Li, S.; Jiang, H.; Yang, K.; Zhang, Z.; Li, S.; Luo, N.; Liu, Q.; Wei, R. Three-dimensional hierarchical graphene/ $\mathrm{TiO}_{2}$ composite as high-performance electrode for supercapacitor. J. Alloys Compd. 2018, 746, 670-676. [CrossRef]

17. Zhang, M.; Sha, J.; Miao, X.; Liu, E.; Shi, C.; Li, J.; He, C.; Li, Q.; Zhao, N. Three-dimensional graphene anchored $\mathrm{Fe}_{2} \mathrm{O}_{3} @ \mathrm{C}$ core-shell nanoparticles as supercapacitor electrodes. J. Alloys Compd. 2017, 696, 956-963. [CrossRef]

18. Zhang, C.; Kuila, T.; Kim, N.H.; Lee, S.H.; Lee, J.H. Facile preparation of flower-like $\mathrm{NiCo}_{2} \mathrm{O}_{4} /$ three dimensional graphene foam hybrid for high performance supercapacitor electrodes. Carbon 2015, 89, 328-339. [CrossRef]

19. Xu, Y.; Huang, X.; Lin, Z.; Zhong, X.; Huang, Y.; Duan, X. One-step strategy to graphene/Ni(OH $)_{2}$ composite hydrogels as advanced three-dimensional supercapacitor electrode materials. Nano Res. 2013, 6, 65-76. [CrossRef]

20. Li, K.; Huang, Y.; Liu, J.; Sarfraz, M.; Agboola, P.O.; Shark, I.; Xu, Y. A three-dimensional graphene framework-enabled high-performance stretchable asymmetric supercapacitor. J. Mater. Chem. A 2018, 6, 1802-1808. [CrossRef]

21. Wu, J.; Zhang, Q.; Wang, J.; Huang, X.; Bai, H. A self-assembly route to porous polyaniline/reduced graphene oxide composite materials with molecular-level uniformity for high-performance supercapacitors. Energy Environ. Sci. 2018, 11, 1280-1286. [CrossRef]

22. Pruna, A.I.; Cárcel, A.C.; Benedito, A.; Giménez, E. The effect of solvothermal conditions on the properties of three-dimensional N-doped graphene aerogels. Nanomaterials 2019, 9, 350. [CrossRef] [PubMed]

23. Xiong, C.; Li, B.; Lin, X.; Liu, H.; Xu, Y.; Mao, J.; Duan, C.; Li, T.; Ni, Y. The recent progress on three-dimensional porous graphene-based hybrid structure for supercapacitor. Compos. Part B Eng. 2019, 165, 10-46. [CrossRef]

24. Huo, J.; Zheng, P.; Wang, X.; Guo, S. Three-dimensional sulphur/nitrogen co-doped reduced graphene oxide as high-performance supercapacitor binder-free electrodes. Appl. Surf. Sci. 2018, 442, 575-580. [CrossRef]

25. Mao, S.; Lu, G.; Chen, J. Three-dimensional graphene-based composites for energy applications. Nanoscale 2015, 7, 6924-6943. [CrossRef] [PubMed]

26. Zhou, J.; Huang, Y.; Cao, X.; Ouyang, B.; Sun, W.; Tan, C.; Zhang, Y.; Ma, Q.; Liang, S.; Yan, Q.; et al. Two-dimensional $\mathrm{NiCo}_{2} \mathrm{O}_{4}$ nanosheet-coated three-dimensional graphene network for high-rate, long-cycle-life supercapacitors. Nanoscale 2015, 7, 7035-7039. [CrossRef]

27. He, S.; Chen, W. 3D graphene nanomaterials for binder-free supercapacitors: Scientific design for enhanced performance. Nanoscale 2015, 7, 6957-6990. [CrossRef]

28. Zhang, L.; Shi, G. Preparation of highly conductive graphene hydrogels for fabricating supercapacitors with high rate capability. J. Phys. Chem. C 2011, 115, 17206-17212. [CrossRef]

29. Wu, X.; Zhou, J.; Xing, W.; Wang, G.; Cui, H.; Zhuo, S.; Xue, Q.; Yan, Z.; Qiao, S.Z. High-rate capacitive performance of graphene aerogel with a superhigh C/O molar ratio. J. Mater. Chem. 2012, 22, 23186-23193. [CrossRef]

30. Luo, P.; Guan, X.; Yu, Y.; Li, X.; Yan, F. Hydrothermal synthesis of graphene quantum dots supported on three-dimensional graphene for supercapacitors. Nanomaterials 2019, 9, 201. [CrossRef] [PubMed]

31. Ye, S.; Feng, J.; Wu, P. Deposition of three-dimensional graphene aerogel on nickel foam as a binder-free supercapacitor electrode. ACS Appl. Mater. Interfaces 2013, 5, 7122-7129. [CrossRef] [PubMed]

32. Gao, T.; Xu, W.; Gong, L.; Wang, Z.; Yang, Z.; Song, Y.; Xiong, Y. Folded three-dimensional graphene with uniformly distributed mesopores for high-performance supercapacitors. RSC Adv. 2015, 5, 33767-33771. [CrossRef]

33. Kuila, T.; Mishra, A.K.; Khanra, P.; Kim, N.H.; Lee, J.H. Recent advanced in the efficient reduction of graphene oxide and its application as energy storage electrode materials. Nanoscale 2013, 5, 52-71. [CrossRef] 
34. Kang, S.; Lim, K.; Park, H.; Park, J.B.; Park, S.C.; Cho, S.P.; Kang, K.; Hong, B.H. Roll-to-roll laser-printed graphene-graphitic carbon electrodes for high-performance supercapacitors. ACS Appl. Mater. Interfaces 2018, 10, 1033-1038. [CrossRef]

35. Xu, Y.; Lin, Z.; Zhong, X.; Huang, X.; Weiss, N.O.; Huang, Y.; Duan, X. Holey graphene frameworks for highly efficient capacitive energy storage. Nat. Commun. 2014, 5, 4554. [CrossRef] [PubMed] 